\title{
Synthesis and Characterization of Ordered and Disordered Mesoporous Alumina as High-Performance Molybdenum-99 Adsorbents
}

\author{
I. Saptiama $^{1 *}$, F. Rindiyantono ${ }^{1}$, A. Aries ${ }^{1}$, Y. V. Kaneti ${ }^{2}$, M. Iqbal ${ }^{2,3}$ \\ ${ }^{I}$ Center for Radioisotope and Radiopharmaceutical Technology, National Nuclear Energy Agency (BATAN), \\ Puspiptek Area Serpong, Tangerang Selatan 15314, Indonesia \\ ${ }^{2}$ International Center for Materials Nanoarchitectonics (WPI-MANA)-NIMS, 1-1 Namiki, Tsukuba, Ibaraki 305-0044, Japan \\ ${ }^{3}$ Engineering Physics Department and Research Centre for Nanoscience and Nanotechnolog, Institut Teknologi Bandung, \\ Jl. Ganesa No.10, Bandung 40132, Indonesia
}

\section{ARTICLE INFO}

\section{Article history:}

Received 5 November 2019

Received in revised form 4 January 2021

Accepted 6 January 2021

\section{Keywords:}

Molybdenum-99

Technetium-99m

Diagnostic

Mesoporous

Alumina

\begin{abstract}
A B S T R A C T
Molybdenum-99 $\left({ }^{99} \mathrm{Mo}\right)$ is the parent radioisotope of technetium-99m $\left({ }^{99 \mathrm{~m}} \mathrm{Tc}\right)$, an essential medical radioisotope for diagnostic agents in nuclear medicine. In ${ }^{99} \mathrm{Mo} /{ }^{99 \mathrm{~m}} \mathrm{Tc}$ generator, a chromatography column system with ${ }^{99} \mathrm{Mo}$ adsorbent as a filler is usually used to produce ${ }^{99 \mathrm{~m}} \mathrm{Tc}$ in hospitals. However, it is still challenging to find high-performance adsorbents for Mo adsorption. We have synthesized both ordered and disordered mesoporous alumina and compared their performance as ${ }^{99}$ Mo adsorbents. These materials were prepared via a soft-templated method using a triblock copolymer as the template, followed by air calcination at $400{ }^{\circ} \mathrm{C}$. The amount of nitric acid $\left(\mathrm{HNO}_{3}\right)$ and the drying time were adjusted systematically to synthesize the ordered mesoporous alumina. The obtained ordered and disordered mesoporous alumina were characterized by low-and wide-angle X-ray diffractions (XRD), nitrogen adsorption-desorption, thermogravimetric analysis (TGA), scanning electron microscopy (SEM), and transmission electron microscopy (TEM). The ${ }^{99}$ Mo adsorption capacities of these materials were evaluated by using the batch method. The experimental results show that the ordered mesoporous alumina has a higher ${ }^{99} \mathrm{Mo}$ adsorption capacity of $72.06 \mathrm{mg}$ (Mo) $\mathrm{g}^{-1}$ than the disordered mesoporous alumina $\left(50.12 \mathrm{mg}(\mathrm{Mo}) \mathrm{g}^{-1}\right)$. The results indicate the excellent potential of ordered mesoporous alumina as an adsorbent for the ${ }^{99} \mathrm{Mo} /{ }^{99 \mathrm{~m}} \mathrm{Tc}$ generator column.
\end{abstract}

(C) 2021 Atom Indonesia. All rights reserved

\section{INTRODUCTION}

According to the pore size, materials can be classified as microporous, mesoporous, and macroporous materials. Microporous materials possess pore size less than $2 \mathrm{~nm}$, while mesoporous materials exhibit pore size between $2 \mathrm{~nm}$ and $50 \mathrm{~nm}$, and macroporous materials exhibit pore size greater than $50 \mathrm{~nm}$ [1]. Mesoporous materials have been used in a wide variety of applications, including catalysis [2], adsorption [3-6], drug delivery systems $[7,8]$, gas sensors $[9,10]$, energy storage $[11,12]$, and radionuclides separation $[13,14]$. The ordered mesoporous material was prepared using a softtemplating method, where the templates were

\footnotetext{
*Corresponding author

E-mail address: indra.saptiama@ batan.go.id

DOI: https://doi.org/10.17146/aij.2021.1000
}

formed using surfactant micelles as structuredirecting agents. The resulting mesoporous materials exhibited narrow pore size distribution, high surface area, and tunable pore size, depending on the preparation method. Since then, the number of studies on mesoporous materials has greatly increased [15-17]. Ordered mesoporous materials are preferred as support materials to non-ordered, noncrystalline materials due to the ease of functionalization with organic compounds.

Mesoporous alumina is an intriguing material with broad uses because of its unique adsorption, catalytic, and physical properties; thus, the control of the properties of this material is the key topic of current research. In general, mesoporous alumina has been prepared by template-assisted methods by utilizing various templates, including cationic and anionic surfactants, nonionic surfactants, and ionic 
liquids [18-20]. The template-assisted synthesis of mesoporous materials typically involves (1) template assembly, (2) template-directed synthesis of materials, and (3) template removal [1]. The "soft-templated" methods have several advantages, including fine-tuning the structure of inorganic materials and mechanically strengthening the organic functional structures. Pluronic P123 $\left(\mathrm{EO}_{20}-\mathrm{PO}_{70}-\mathrm{EO}_{20}\right)$ is a commercial surfactant used as a template for synthesizing mesoporous alumina with larger pores. The pore size of mesoporous alumina determines its functional performance, especially in adsorption and separation.

Since its discovery in 1937 by Carlo Perrier and Emilio Segre, Technetium-99m $\left({ }^{99 \mathrm{~m}} \mathrm{Tc}\right)$ has been commonly used in medical imaging for diagnostic purposes [21,22]. The most exciting feature of ${ }^{99 \mathrm{~m}} \mathrm{Tc}$ is its short half-life $\left(T_{1 / 2}\right)$ of $6 \mathrm{~h}$ and its ability to emit pure gamma-ray with an energy of $140 \mathrm{keV}$ that is suitable for imaging by single-photon emission computed tomography (SPECT) $[23,24] .{ }^{99 \mathrm{~m}} \mathrm{Tc}$ is an artificial radionuclide resulted from the radionuclide decay of $\beta^{-}$-emitter molybdenum-99 $\left({ }^{99} \mathrm{Mo}\right)$. There are two primary methods for producing ${ }^{99} \mathrm{Mo}$, namely (1) irradiation of uranium-235 $\left({ }^{235} \mathrm{U}\right)$ from highly- or lowly-enriched uranium via route ${ }^{235} \mathrm{U}$ (n,f) ${ }^{99} \mathrm{Mo}$, and (2) irradiation of natural molybdenum $\left(\mathrm{MoO}_{3}\right)$ via route ${ }^{98} \mathrm{Mo}(\mathrm{n}, \gamma){ }^{99} \mathrm{Mo}[25]$. Commonly, ${ }^{99 \mathrm{~m}} \mathrm{Tc}$ is obtained from ${ }^{99}$ Mo produced by the first method because the ${ }^{99}$ Mo radionuclide as a fission product has high specific activity [26]. However, the separation process of ${ }^{99} \mathrm{Mo}$ from ${ }^{235} \mathrm{U}$ fission reaction is complicated and expensive and requires extensive purification before use, while also producing large amounts of radioactive waste with a long half-life [27]. Furthermore, the shortage of ${ }^{99} \mathrm{Mo}$ is a severe problem due to the restrictions on the distribution of HEU-235 imposed by the United States Congress to prevent its abuse and prolong the supply of ${ }^{99} \mathrm{Mo}$. Therefore, an alternative method is needed to address the ${ }^{99} \mathrm{Mo}$ shortage. Neutron activation of ${ }^{98} \mathrm{Mo}$ in a nuclear reactor is relatively simple in postirradiation processing, safety, and waste management. Nevertheless, ${ }^{99}$ Mo obtained by this method produces low specific activity due to the low abundance of natural ${ }^{98} \mathrm{Mo}(24.2 \%)$. Therefore, it is desirable to develop materials with high adsorption capacities for ${ }^{99} \mathrm{Mo}$.

In this work, we have synthesized both disordered and ordered mesoporous alumina by the soft-templating method with the use of symmetric triblock copolymer of poly(ethylene oxide) (PEO) and poly(propylene oxide) (PPO) (Pluronic-123) as a soft template. The amount of nitric acid and the drying method was optimized to obtain highly ordered mesoporous alumina. The disordered and ordered mesoporous alumina were characterized by small-angle X-ray scattering (SAXS), wide-angle X-ray diffraction (XRD), scanning electron microscopy (SEM), transmission electron microscopy (TEM), and nitrogen adsorptiondesorption. Finally, the ${ }^{99} \mathrm{Mo}$ adsorption properties of both disordered and ordered mesoporous alumina were evaluated using the batch method.

\section{EXPERIMENTAL METHODS}

\section{Materials}

Aluminum isopropoxide $\left(\mathrm{C}_{9} \mathrm{H}_{21} \mathrm{AlO}_{3}, 98 \%\right)$, aluminium(III) nitrate nonahydrate $\left(\mathrm{Al}\left(\mathrm{NO}_{3}\right)_{3} .9 \mathrm{H}_{2} \mathrm{O}\right.$, $99.5 \%)$, and ethanol $\left(\mathrm{C}_{2} \mathrm{H}_{5} \mathrm{OH}, 99.9 \%\right)$ were purchased from Wako Pure Chemical Industries, Ltd., Japan. Poly(ethylene glycol)-block-poly (propylene glycol)-block-poly(ethylene glycol) or PEG-PPG-PEG or Pluronic P123, molybdenum(VI) oxide $\left(\mathrm{MoO}_{3}\right)$, and nitric acid $\left(\mathrm{HNO}_{3}\right)$ were obtained from Sigma-Aldrich. All chemicals were used without further purification.

\section{Synthesis of ordered and disordered mesoporous alumina}

Mesoporous alumina was synthesized as follows: $20 \mathrm{~mL}$ of ethanol was added to $1 \mathrm{~g}$ of Pluronic P123 under vigorous stirring in a flask. After 1 hour, $2 \mathrm{~g}$ of aluminum isopropoxide, and $400 \mathrm{mg}$ of aluminum nitrate were added, and the mixture was maintained at room temperature for 30 minutes. Different amounts of concentrated nitric acid $\left(\mathrm{HNO}_{3}\right)$ were then added to the sol, and the mixture was kept under gentle stirring for 24 hours at room temperature. Next, the mixture was poured into Petri dishes to evaporate the solvent in the oven at $60{ }^{\circ} \mathrm{C}$ and at room temperature with different drying times. Finally, the obtained white powders were calcined in air at $400{ }^{\circ} \mathrm{C}$ for 4 hours with a heating rate of $1{ }^{\circ} \mathrm{C} \min ^{-1}$. Table 1 summarizes the mesoporous alumina samples produced in this work.

Table 1. List of mesoporous alumina samples.

\begin{tabular}{cccc}
\hline Samples & $\begin{array}{c}\mathbf{H N O}_{3} \\
(\boldsymbol{\mu L})\end{array}$ & $\begin{array}{c}\text { Drying } \\
\text { Times }\end{array}$ & $\begin{array}{c}\text { Drying } \\
\text { Temperature }\left({ }^{\circ} \mathbf{C}\right)\end{array}$ \\
\hline MA-1 & 0 & $24 \mathrm{~h}$ & 60 \\
MA-2 & 250 & $24 \mathrm{~h}$ & 60 \\
MA-3 & 500 & $24 \mathrm{~h}$ & 60 \\
MA-4 & 750 & $24 \mathrm{~h}$ & 60 \\
MA-5 & 1000 & $24 \mathrm{~h}$ & 60 \\
MA-6 & 1000 & $48 \mathrm{~h}$ & 60 \\
MA-7 & 1000 & $6 \mathrm{~d}$ & RT \\
\hline
\end{tabular}

h: hours, d: days, RT: room temperature 


\section{Characterization}

Scanning electron microscopy images were taken using a Hitachi S-4800 field emission SEM. Transmission electron microscopy images were obtained with a JEOL-3000F TEM operated at an accelerating voltage of $200 \mathrm{kV}$. The TEM samples were prepared by dispersing the samples in ethanol by ultrasonication before the samples were dropped onto a carbon-coated microgrid. Small-angle X-ray scattering (SAXS) and wide-angle XRD patterns were acquired with NANOviewer spectrometer (Rigaku) and X-ray diffractometer RINT-2000 (Rigaku), respectively. Nitrogen $\left(\mathrm{N}_{2}\right)$ adsorptiondesorption measurements of the samples were performed at $77 \mathrm{~K}$ using a BELSORP-mini II sorption system. The multipoint BET method at a relative pressure range of $0.05-0.3$ was applied to calculate the specific surface area, and the BarrettJoyner-Halenda (BJH) method was used to calculate the total pore volume. Before the measurement, all the samples were degassed under vacuum at 150 ${ }^{\circ} \mathrm{C}$ for 24 hours. Thermogravimetric analyses (TGA) were carried out with a Hitachi HT-Seiko Instrument Exter 6300 TG/DTA. The measurements were conducted from room temperature to $1000{ }^{\circ} \mathrm{C}$ under air atmosphere with a heating rate of $10^{\circ} \mathrm{C} \mathrm{min}^{-1}$.

\section{Molybdenum-99 adsorption measurements}

The ${ }^{99}$ Mo adsorption capacities of the samples were evaluated using the batch method. The nonradioactive molybdenum solution was prepared by dissolving molybdenum(VI) oxide $\left(\mathrm{MoO}_{3}\right)$ in $4 \mathrm{~N}$ sodium hydroxide. In brief, $20 \mathrm{mg}$ of the sample was added to $2.0 \mathrm{~mL}$ of sodium molybdate solution $\left(\mathrm{Na}_{2} \mathrm{MoO}_{4}\right)$ with a concentration of $10 \mathrm{mg}$ (Mo) $\mathrm{mL}^{-1}$ and spiked with $\sim 370 \mathrm{kBq}$ of ${ }^{99} \mathrm{Mo}$. The $\mathrm{pH}$ of the solution was adjusted to 3 by adding nitric acid $\left(\mathrm{HNO}_{3}\right)$ in a small glass vial at room temperature. Next, the suspension was slightly shaken for 1 hour, and the solid was filtered. A multichannel analyzer was used to measure the concentration of ${ }^{99} \mathrm{Mo}$ and calculate each sample's the Mo adsorption.

\section{RESULTS AND DISCUSSION}

Low-angle XRD profiles of the mesoporous alumina samples with increasing $\mathrm{HNO}_{3}$ are shown in Fig. 1. The MA-4 and MA-5 patterns show a single broad peak, indicating the poorly ordered mesoporous structure. The 2D images from the CCD camera also show unclear rings, suggesting the less periodic structure in these samples. For samples MA-1, MA-2, and MA-3, with lower $\mathrm{HNO}_{3}$ additions, no peak is observed, as seen in
Figs. 1 (a)-(c), thus indicating their disordered mesoporous structure.

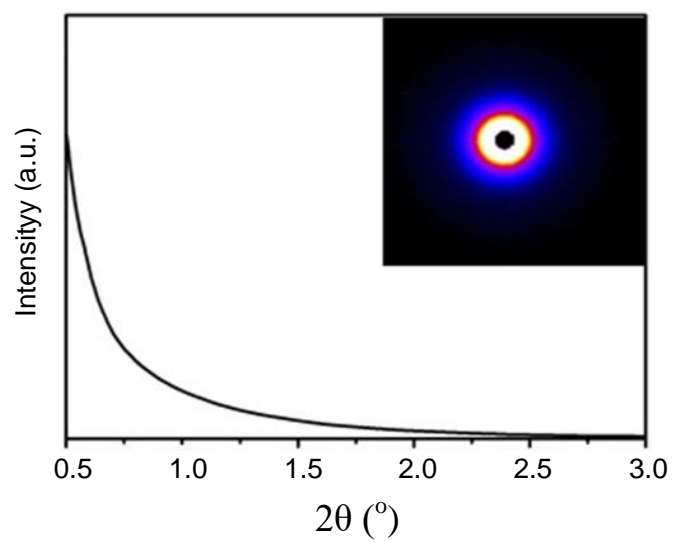

(a)

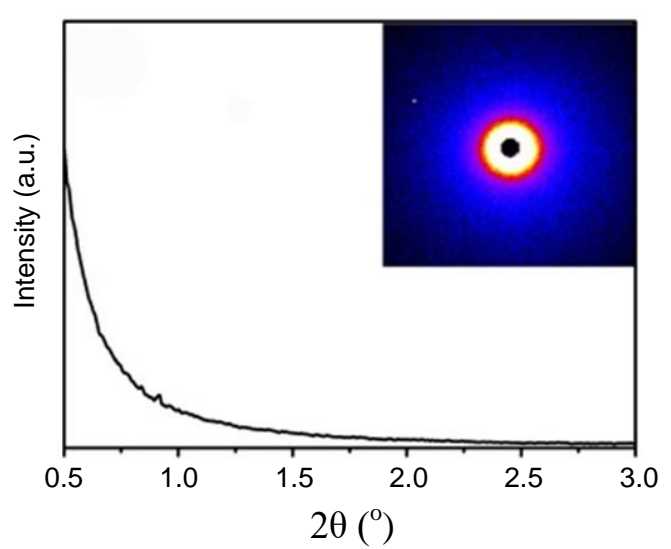

(b)

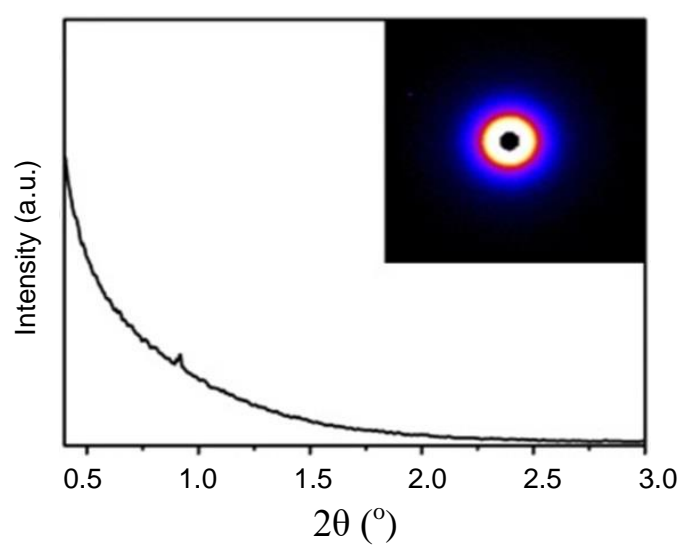

(c)

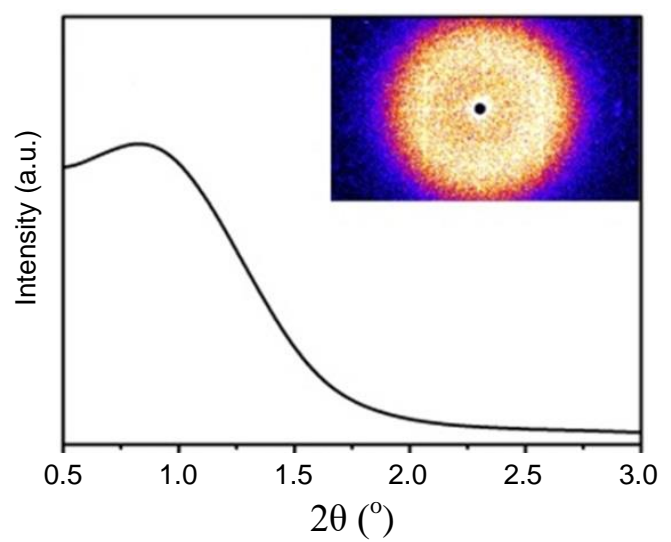

(d) 


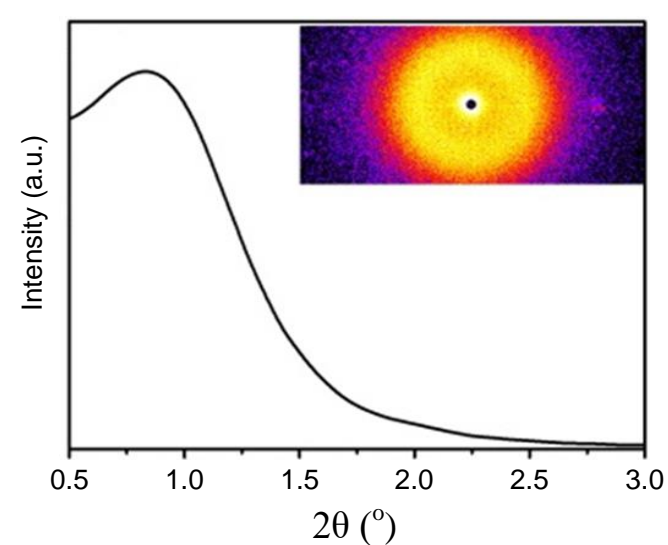

(e)

Fig. 1. Low-angle XRD patterns and 2D images taken from the CCD camera (insets) for (a) MA-1, (b) MA-2, (c) MA-3, (d) MA-4, (e) MA-5.

As shown by the wide-angle XRD patterns in Fig. 2, no apparent peaks are observed in the diffraction patterns of MA-1 to MA-5, indicating their amorphous nature. It has been suggested that the ordered mesoporous structure is formed by a self-assembly process, in which the cross-linked aluminum species arrange around the triblock copolymer [28]. The condensation step has to be carefully controlled to achieve an ordered mesoporous structure. Nitric acid serves as a $\mathrm{pH}$ controller and coordination agent in the synthesis system to preserve medium acidity [29]. In acidic conditions, protons promote a connection between polyethylene oxide (PEO) blocks and aluminum precursors to form the mesoporous structures [30]. Moreover, the concentration of the acid controls the rate of the condensation reaction. The acidic environment may reduce the condensation rate and provide enough time for the polymer blocks to form an ordered mesoporous structure [31]. Nevertheless, the degree of ordering of the mesopores in these samples is still not so high.

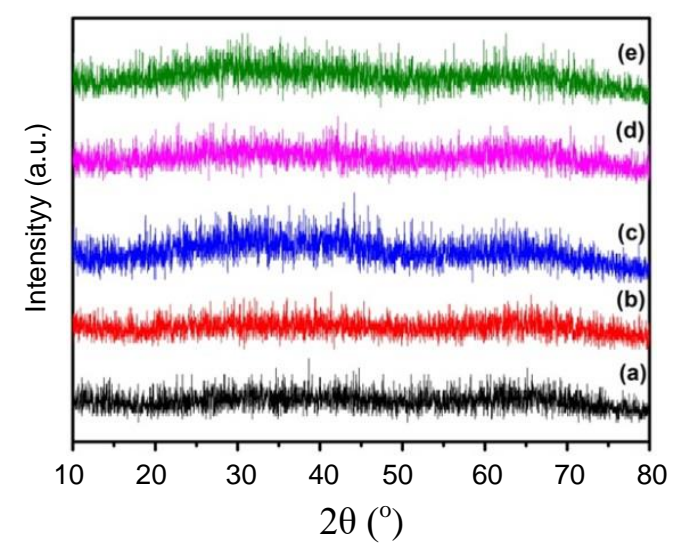

Fig. 2. Wide-angle XRD patterns for (a) MA-1, (b) MA-2, (c) MA-3, (d) MA-4, (e) MA-5.
To improve the ordering degree, the drying conditions, especially the drying time and the drying temperature, were systemically controlled. Samples MA-6 and MA-7 were obtained by prolonging the drying time and lowering the drying temperature down to room temperature. Interestingly, these samples exhibit slightly sharper peaks and more clear rings (Fig. 3) compared to other samples (MA-1 to MA-5), indicating the higher degree of ordering of the mesopores and the existence of periodic mesoporosity in these two samples. The XRD patterns of MA-6 and MA-7 show peaks at $1.16^{\circ}(\mathrm{d}=7.6 \mathrm{~nm})$ and $1.23^{\circ}$ $(\mathrm{d}=7.1 \mathrm{~nm})$, respectively.

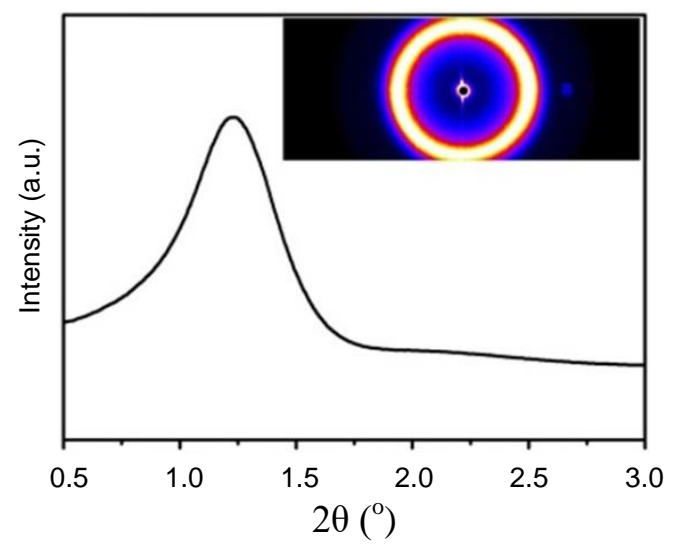

(a)

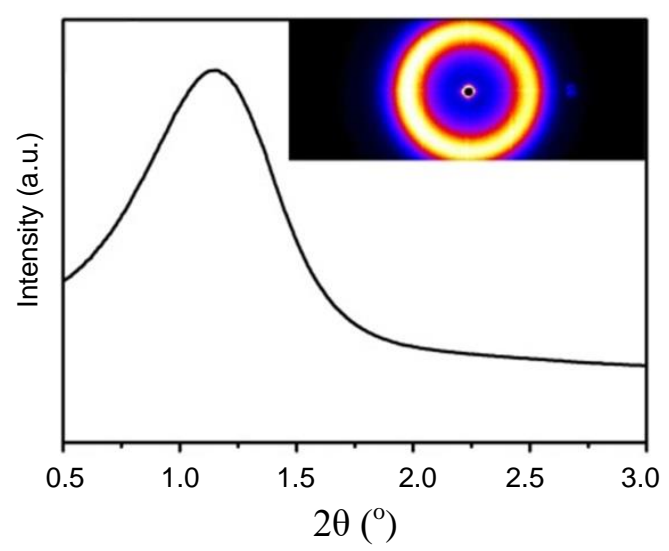

(b)

Fig. 3. Low-angle XRD patterns and $2 D$ images taken from the CCD camera for (a) MA-6, (b) MA-7.

Assuming that an ideal 2D hexagonal mesostructure is formed, the pore-pore distance is estimated to be ca. $8.8 \mathrm{~nm}$ and $8.3 \mathrm{~nm}$ for MA-6 and MA-7, respectively. The crystallinity of the samples was characterized by wide-angle XRD, as shown in Fig. 4. Again, no obvious peaks can be observed, revealing that most of the frameworks are still amorphous. The prolonged drying time and lower drying temperature result in highly ordered mesopores due to the well-controlled hydrolysis conditions. 


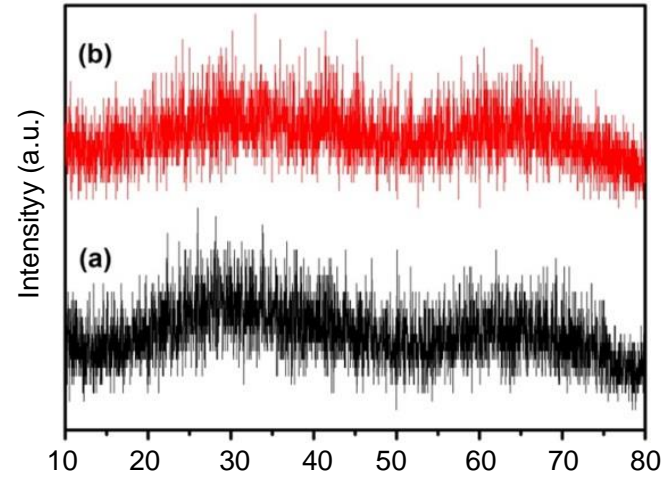

Fig. 4. Wide-angle XRD patterns for (a) MA-6, (b) MA-7.

Figure 5 shows the nitrogen $\left(\mathrm{N}_{2}\right)$ adsorptiondesorption isotherms and pore size distribution curves of all mesoporous alumina samples. The textural characteristics of these samples are summarized in Table 2. All the isotherm of resulting samples exhibit a type IV. Except for the adsorption isotherms of MA-1, MA-2, and MA-3, which show relatively small adsorption, capillary condensation in small pore channels, and broad pore size distribution, the isotherms of the remaining mesoporous alumina samples (MA-4 to MA-7) display steep capillary condensation steps, indicating the relatively uniform mesopores and narrow pore size distribution, as seen in Fig. 5 (inset) [4,32]. The average pore diameters of MA-4, MA-5, MA-6, and MA-7 (i.e., ordered mesoporous alumina samples) are $4.27,5.41,4.19$, and $4.76 \mathrm{~nm}$, respectively. In comparison, the average pore diameters of MA-1, MA-2, and MA-3 (i.e., disordered mesoporous alumina samples) are 2.30, 2.59, and $2.91 \mathrm{~nm}$, respectively. This trend reveals the increase in average pore diameter with increasing $\mathrm{HNO}_{3}$ addition. As discussed earlier, $\mathrm{HNO}_{3}$ addition not only leads to acidic conditions but also affects the micelle size. The increased amount of $\mathrm{HNO}_{3}$ leads to an increase of micelle size due to the affinity of protons to the PEO blocks and the increase of nitric ion concentration at the water interface of mesoporous material, thus leading to a larger average pore diameter [30,31]. Due to the higher surface areas than the remaining samples, MA-1 and MA-6 were selected as the representative samples for disordered and ordered mesoporous alumina, respectively.

Table 2. Textural characteristics of mesoporous alumina samples.

\begin{tabular}{|c|c|c|c|c|}
\hline Sample & $\begin{array}{c}\text { Surface area } \\
\left(\mathrm{m}^{2} \mathrm{~g}^{-1}\right)\end{array}$ & $\begin{array}{c}\text { Pore volume } \\
\left(\mathrm{cm}^{3} \mathrm{~g}^{-1}\right)\end{array}$ & $\begin{array}{c}\text { Average pore } \\
\text { diameter }(\mathbf{n m})\end{array}$ & $\begin{array}{c}\text { Ordered/ } \\
\text { disordered }\end{array}$ \\
\hline MA-1 & 268 & 0.47 & 2.30 & Disordered \\
\hline MA-2 & 127 & 0.35 & 2.59 & Disordered \\
\hline MA-3 & 195 & 0.25 & 2.91 & Disordered \\
\hline MA-4 & 211 & 0.25 & 4.27 & Low-ordered \\
\hline MA-5 & 256 & 0.38 & 5.41 & Low-ordered \\
\hline MA-6 & 231 & 0.29 & 4.19 & High-ordered \\
\hline MA-7 & 216 & 0.27 & 4.76 & High-ordered \\
\hline
\end{tabular}

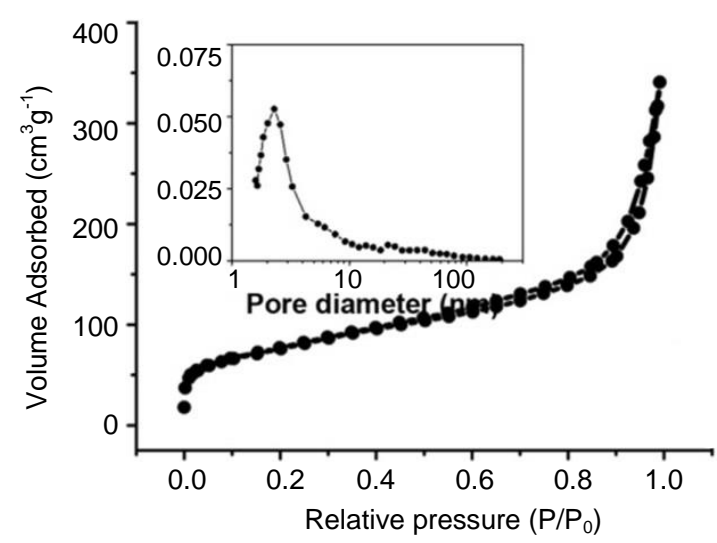

(a)

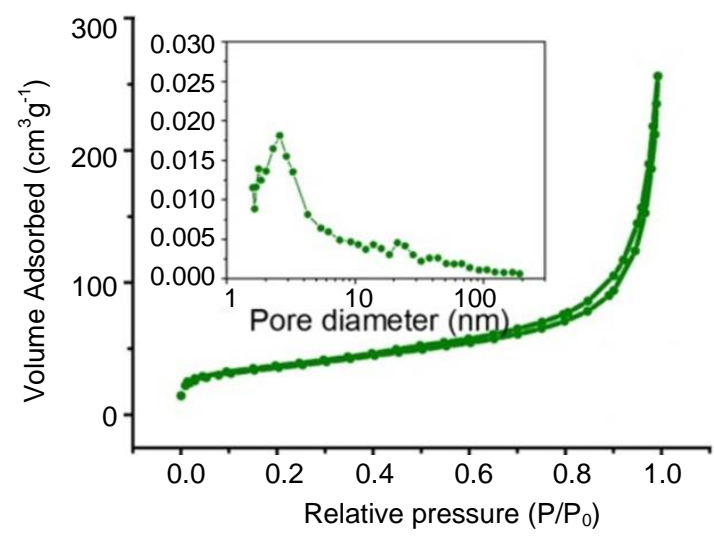

(b)

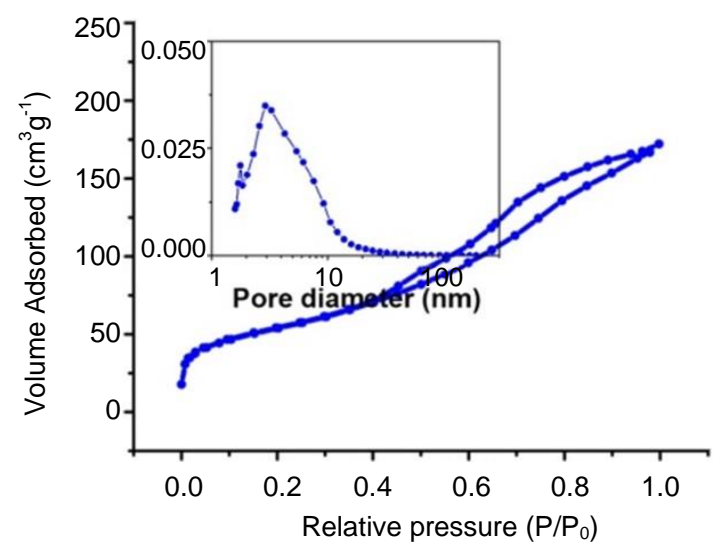

(c)

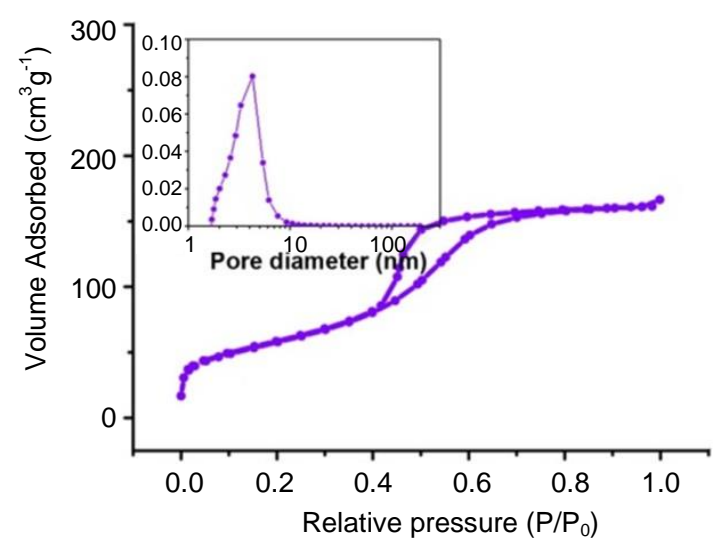

(d) 


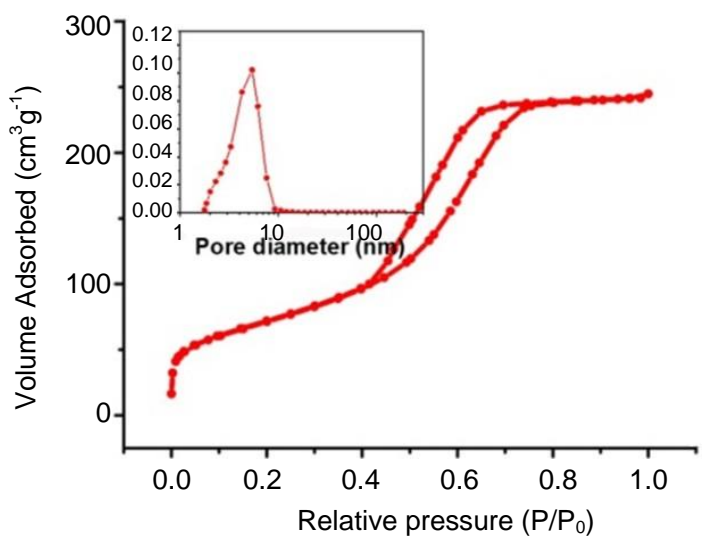

(e)

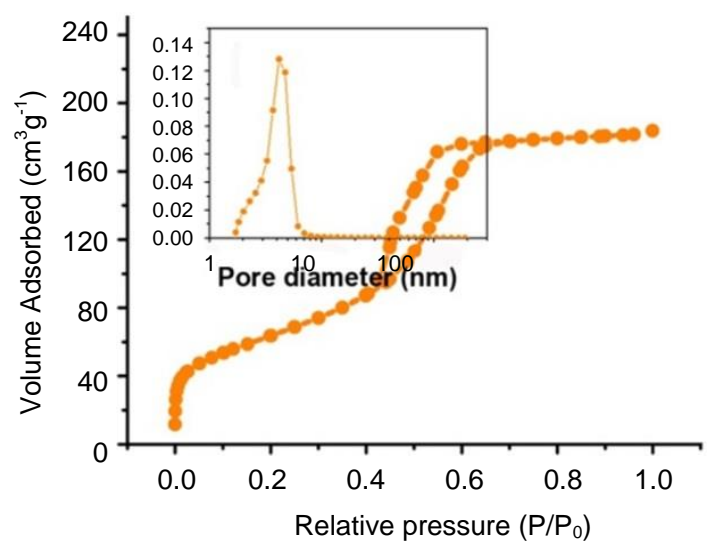

(f)

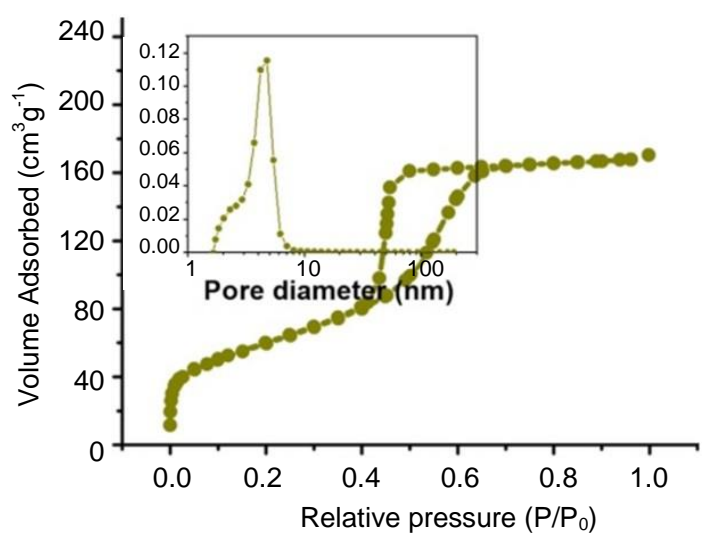

(g)

Fig. 5. Nitrogen $\left(\mathrm{N}_{2}\right)$ adsorption-desorption isotherms and Barrett-Joyner-Halenda (BJH) pore size distribution curves (inset) of the mesoporous alumina samples: a) MA-1,b) MA-2, c) MA-3, d) MA-4, e) MA-5, f) MA-6, g) MA-7.

SEM images of the MA-1 and MA- 6 samples are displayed in Fig. 6. It can be observed from Figs. 6(a) and 6(b) that disordered mesoporous alumina with a rough appearance is obtained without $\mathrm{HNO}_{3}$ addition. Meanwhile, the ordered mesoporous alumina obtained using the optimal amount of $\mathrm{HNO}_{3}$ exhibits a relatively smooth surface, as shown in Figs. 6(c) and 6(d). TEM images of MA-6 obtained at an optimized $\mathrm{HNO}_{3}$ and aging condition is presented in Figs. 7 (d)-(f). In agreement with the SAXS pattern, the TEM images in Figs. 7 (d)-(f) confirm the formation of highly ordered mesoporous structure. Meanwhile, MA-1, which was synthesized without $\mathrm{HNO}_{3}$, displays a dense structure and an irregular shape (Figs. 7 (a)-(c)), indicating its disordered mesoporous structure.

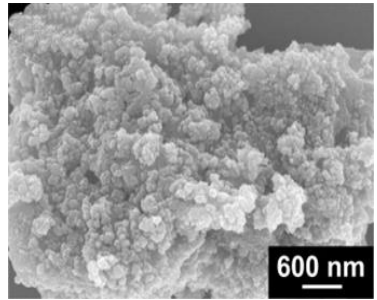

(a)

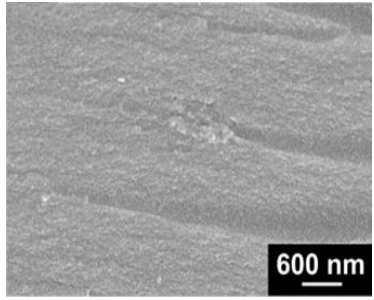

(c)

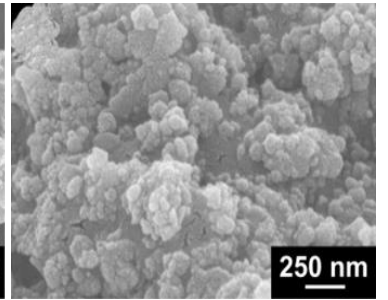

(b)

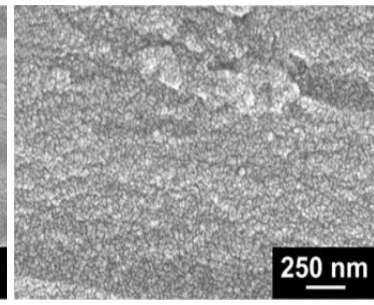

(d)
Fig. 6. Low- and high-magnification SEM images of (a, b) MA-1 (disordered mesoporous) and (c, d) MA-6 (ordered mesoporous).

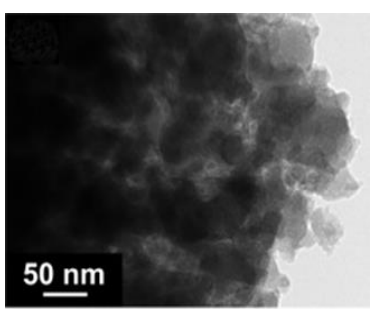

(a)

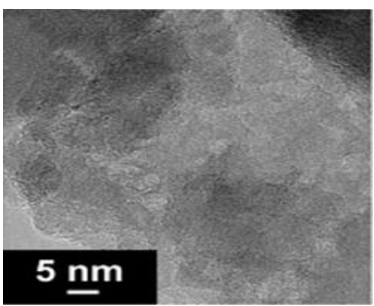

(c)

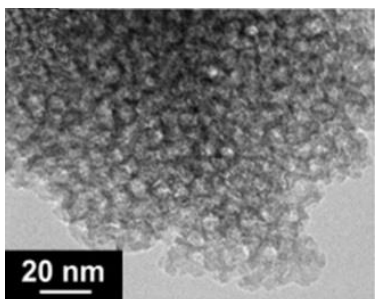

(e)

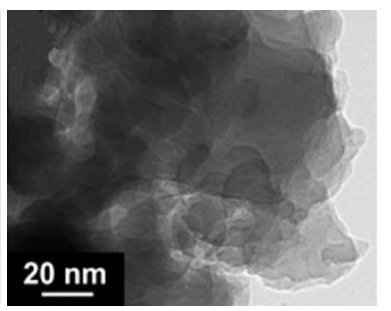

(b)

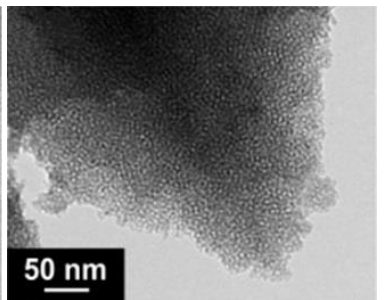

(d)

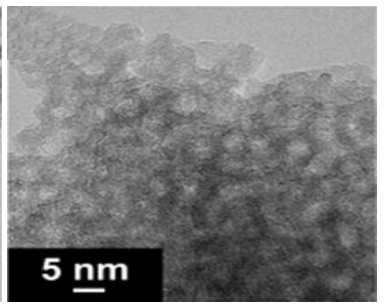

(f)
Fig. 7. Low- and high-magnification TEM, HRTEM images of MA-1 (a, b, c) and MA-6 (d, e, f). 
MA-1 and MA-6 exhibit similar thermal decomposition behaviors, as seen in Fig. 8. For both samples, three main weight loss steps are observed. The first weight loss at below around $150{ }^{\circ} \mathrm{C}$ is attributed to the removal of physisorbed and chemisorbed water molecules; the second weight loss step between $150{ }^{\circ} \mathrm{C}$ and $600{ }^{\circ} \mathrm{C}$ is attributed to the conversion of boehmite into transition alumina and the decomposition of organic constituents; the last weight loss step is assigned to the dehydration of transition alumina $[5,26,29]$. Furthermore, a robust exothermic peak is observed between 200 and $250{ }^{\circ} \mathrm{C}$ in the DTA curves of MA-1 and MA-6, indicating the oxidation, decomposition, and elimination of the template [31].

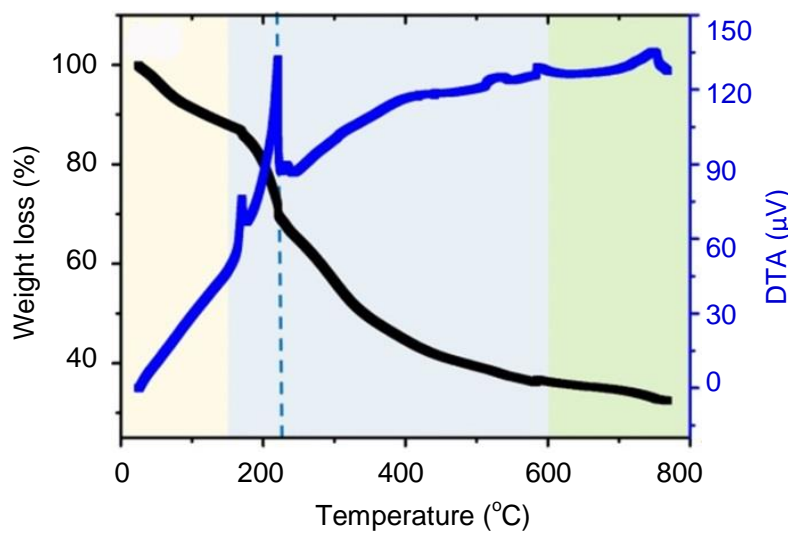

(a)

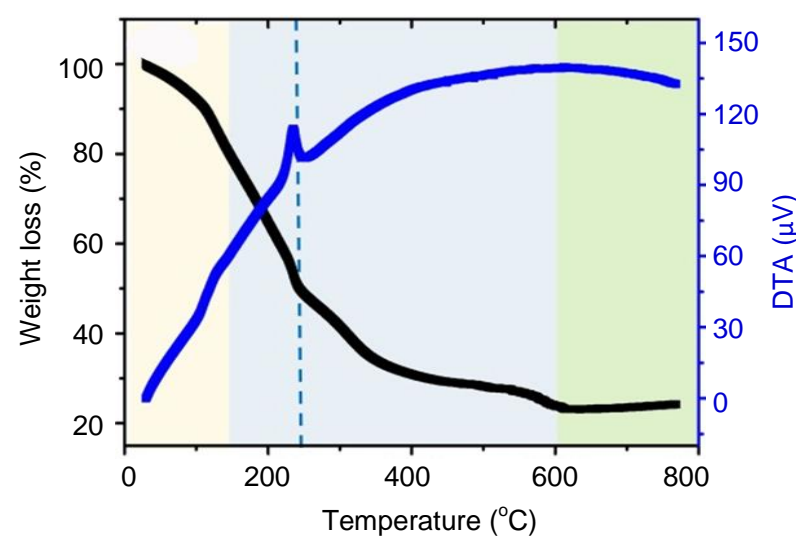

(b)

Fig. 8. TG-DTA curves for (a) MA-1 and (b) MA-6.

Molybdenum adsorption experiments have been conducted using MA-1 and MA-6 as representative samples via the batch method (Table 3) to examine their potential as adsorbents for ${ }^{99} \mathrm{Mo} /{ }^{99 \mathrm{~m}} \mathrm{Tc}$ generator columns. The Mo adsorption experiments were conducted at an optimum $\mathrm{pH}$ of 3 based on previous findings [4-6]. Ordered mesoporous alumina (MA-6) shows a higher Mo adsorption capacity of $72.06 \mathrm{mg}$ (Mo) $\mathrm{g}^{-1}$ than disordered mesoporous alumina (MA-1) $(50.12 \mathrm{mg}$ (Mo) $\mathrm{g}^{-1}$ ), despite its slightly lower surface area (Table 2). It has been reported that ordered mesoporous alumina has a higher intra-particle rate constant than disordered mesoporous alumina [33]. The lower intra-particle rate constant of the disordered mesoporous alumina can be attributed to the diffusion resistance inside the mesoporous tunnels of alumina. Initially, the molybdate ion $\left(\mathrm{MoO}_{4}{ }^{-}\right)$was adsorbed by the outer surface of the mesoporous alumina. Once the adsorption at the outer surface reaches saturation, the molybdate ions enter via the pores and are adsorbed by the inward surface of the particles. When the molybdate ions diffuse into the mesoporous alumina pores, the diffusion resistance increased, leading to a decrease in the diffusion rate. With the decrease of molybdate concentration in the solution, the diffusion rate becomes gradually lower, and eventually, the diffusion processes reach equilibrium. MA-6 exhibits ordered mesopores that help decrease the liquid transfer resistance so that the molybdate ions can move easily into the adsorption sites. In contrast, MA-1 has disordered mesopores, as seen in Fig. 5(a), which will restrict the flow of molybdate ions in the solution through the tunnels and lower the adsorption rate.

The Mo adsorption capacities of both samples are more significant than the limit of 2-20 mg (Mo) per $g$ (samples) previously reported for commercial alumina in ${ }^{99} \mathrm{Mo} /{ }^{99 \mathrm{~m}} \mathrm{Tc}$ generators [34]. The ordered mesoporous alumina prepared in this study is better than several other Mo adsorbents, as seen in Table 3. However, polyzirconium compound (PZC) exhibits the highest Mo adsorption capacity among the reported samples, namely $198.7 \mathrm{mg}$ (Mo) per $\mathrm{g}$ (samples). PZC is a zirconium-inorganic polymer able to catch molybdenum dependent on the number of $\mathrm{Cl}$ atoms bonded to $\mathrm{Zr}$ atom in the molecule [35]. It is assumed that PZC structure has a great affinity toward molybdenum ion compare to the other reported materials.

In the future, the as-prepared mesoporous alumina samples will be tested using radioactive ${ }^{99} \mathrm{Mo}$ to assess the practical applicability to ${ }^{99} \mathrm{Mo} /{ }^{99 \mathrm{~m}} \mathrm{Tc}$ generator columns.

Table 3. Comparison of the Mo adsorption capacities of the mesoporous alumina samples prepared in this study with previously reported Mo adsorbents.

\begin{tabular}{lcc}
\hline \multicolumn{1}{c}{ Samples } & $\begin{array}{c}\text { Mo adsorption } \\
\text { capacity }\left(\mathbf{m g ~ g}^{-1}\right)\end{array}$ & Ref. \\
\hline $\begin{array}{l}\text { Ordered mesoporous alumina } \\
\text { (MA-6) }\end{array}$ & 72.06 & This study \\
$\begin{array}{l}\text { Disordered mesoporous alumina } \\
\text { (MA-1) }\end{array}$ & 50.12 & This study \\
Poly-zirconium compound (PZC) & 198.7 & {$[35]$} \\
Nanocrystalline titania & 141.0 & {$[36]$} \\
$\begin{array}{l}\text { Alumina-embedded mesoporous } \\
\text { silica }\end{array}$ & 16.80 & {$[4]$} \\
Mesoporous alumina nanospheres & 56.20 & {$[5]$} \\
\hline
\end{tabular}




\section{CONCLUSION}

In summary, ordered and disordered mesoporous alumina were prepared, characterized, and applied for molybdenum-99 adsorption. Ordered mesoporous alumina was obtained by the softtemplating method with the optimal amount of $\mathrm{HNO}_{3}$ and prolonged drying time. The molybdenum adsorption capacity of the ordered mesoporous alumina sample (MA-6) is higher than that of the disordered mesoporous alumina sample (MA-1). This observation is attributed to ordered mesopores in MA-6, which can enhance the diffusion and transportation of the molybdate ions. These results indicate the excellent potential of ordered mesoporous alumina as ${ }^{99} \mathrm{Mo}$ adsorbent for ${ }^{99} \mathrm{Mo} /{ }^{99 \mathrm{~m}} \mathrm{Tc}$ generators in hospitals.

\section{ACKNOWLEDGMENT}

I.S. gratefully acknowledges the Program for Research and Innovation in Science and Technology (RIST-Pro) scholarship, provided by the Ministry for research, Technology and Higher Education, Republic of Indonesia. The authors also thank Professor Yusuke Yamauchi and the Mesoscale group members at the National Institute of Material Science for helpful suggestions and discussions on material synthesis and characterization.

\section{AUTHOR CONTRIBUTION}

This study was designed, directed and coordinated by I.S. as the principal investigator. He provided conceptual and technical guidance for all aspects of the project. F.R. and A.A. contributed to the mesoporous alumina synthesis and the ${ }^{99} \mathrm{Mo}$ adsorption. Furthermore, Y.V.K. and M.I. performed and analyzed the characterized mesoporous alumina data, including XRD, nitrogen adsorptiondesorption, and SEM. The manuscript was written by I.S and commented on by all authors. All authors read and approved the final version of the paper.

\section{REFERENCES}

1. V. Malgras, Q. Ji, Y. Kamachi et al., Bull. Chem. Soc. Jpn. 88 (2015) 1171.

2. Y.V. Kaneti, S. Tanaka, Y. Jikihara et al., Chem. Commun. 54 (2018) 8514.

3. I. Saptiama, Y.V. Kaneti, Y. Suzuki et al., Bull. Chem. Soc. Jpn. 90 (2017) 1174.
4. I. Saptiama, Y.V. Kaneti, H. Oveisi et al., Bull. Chem. Soc. Jpn. 91 (2018) 195.

5. I. Saptiama, Y.V. Kaneti, Y. Suzuki et al., Small 14 (2018) 1.

6. I. Saptiama, Y.V. Kaneti, B. Yuliarto et al., Chem. Eur. J. 25 (2019) 4843.

7. A.F. Moreira, D.R. Dias and I.J. Correia, Microporous Mesoporous Mater. 236 (2016) 141.

8. A. Hernández-Montoto, A. Llopis-Lorente, M. Gorbe et al., Chem. Eur. J. 25 (2019) 8471.

9. Y. Liu, J. Chen, W. Li et al., J. Colloid Interface Sci. 477 (2016) 54.

10. Y. Li, X. Zhou, W. Luo et al., Adv. Mater. Interfaces 6 (2019) 1.

11. P. Mei, Y.V. Kaneti, M. Pramanik et al., Nano Energy 52 (2018) 336.

12. Y.V. Kaneti, R.R. Salunkhe, N.L.W. Septiani et al., J. Mater. Chem. A 6 (2018) 5971.

13. S. Iqbal and J.-I. Yun, RSC Adv. 8 (2018) 32211 .

14. R. Chakravarty, J. Bahadur, S. Lohar et al., Micropor. Mesopor. Mat. 287 (2019) 271.

15. S.S. Park, M.H. Jung, Y.-S. Lee et al., Mater. Des. 184 (2019) 108187.

16. S. Jafari, H. Derakhshankhah, L. Alaei et al., Biomed. Pharmacother. 109 (2019) 1100.

17. Y.-S. Xiao, B. Zhang, Y.-H. Song et al., Mater. Lett. 223 (2018) 17.

18. S. Said, S. Mikhail and M. Riad, Mater. Sci. Energy Technol. 2 (2019) 288.

19. J.L. Contreras, G. Gómez, B. Zeifert et al., Catal. Today 250 (2015) 72.

20. W. Wu, M. Zhu and D. Zhang, Micropor. Mesopor. Mat. 260 (2018) 9.

21. I. Zolle, Technetium- $99 \mathrm{~m}$ Pharmaceuticals, Preparation and Quality Control in Nuclear Medicine, Springer Berlin Heidelberg New York (2007).

22. M. Pacilio, C. Lauri, D. Prosperi et al., Semin. Nucl. Med. 48 (2018) 261.

23. W.L. Araujo and T.P.R. Campos, Nucl. Instrum. Methods Phys. Res. Sect. A Accel. Spectro. Detect. Assoc. Equip. 782 (2015) 40.

24. P. Martini, A. Boschi, G. Cicoria et al., Appl. Radiat. Isot. 139 (2018) 325. 
25. T.M. Sakr, M.F. Nawar, T.W. Fasih et al., Appl. Radiat. Isot. 129 (2017) 67.

26. A.J. Youker, S.D. Chemerisov, P. Tkac et al., J. Nucl. Med. 58 (2017) 514.

27. T. Takeda, M. Fujiwara, M. Kurosawa et al., J. Radioanal. Nucl. Chem. 318 (2018) 811.

28. L.L. Pérez, S. Perdriau, G. Ten Brink et al., Chem. Mater. 25 (2013) 848.

29. W. Cai, J. Yu, C. Anand et al., Chem. Mater. 23 (2011) 1147.

30. S.M. Grant and M. Jaroniec, J. Mater. Chem. 22 (2012) 86.
31. W. Wu, Z. Wan, W. Chen et al., Micropor. Mesopor. Mat. 217 (2015) 12.

32. H. Maruoka, A. Tomita, L. Zheng et al., Langmuir 34 (2018) 13781.

33. C. Yang, L. Gao, Y. Wang et al., Micropor. Mesopor. Mat. 197 (2014) 156.

34. S. Chattopadhyay, S.S. Das, M.N. Alam et al., J. Radioanal. Nucl. Chem. 313 (2017) 647.

35. M. Tanase, K. Tatenuma, K. Ishikawa et al., Appl. Radiat. Isot. 48 (1997) 607.

36. T.W. Fasih, T.M. Sakr, R.R. Ayoub et al., Sep. Sci. Technol. 51 (2016) 2115. 